\title{
Interaction of Bovine Serum Albumin and Metallothionein
}

\author{
Noel Samson Quiming, ${ }^{a, b}$ Rex Bugante Vergel, ${ }^{c}$ Marilou Gagalac Nicolas, ${ }^{b}$ \\ and James Amador Villanueva*,a,c
}

${ }^{a}$ Institute of Chemistry, University of the Philippines Diliman, Diliman, Quezon City, 1101 Philippines, ${ }^{b}$ Department of Physical Sciences and Mathematics, University of the Philippines Manila, Ermita, Philippines, and 'Natural Sciences Research Institute, University of the Philippines, Diliman Quezon City, 1100 Philippines

(Received July 15, 2004; Accepted September 16, 2004)

\begin{abstract}
Far UV circular dichroism (CD) and fluorescence spectroscopy were used to investigate the interaction between bovine serum albumin (BSA) and metallothionein (MT). Both spectroscopic probes gave proofs on the interaction of the two proteins. At pH 4.0, 7.0 and 9.0, BSA showed a negative increase in ellipticity at the far-UV range in the presence of MT indicating an increase in $\alpha$-helical content and a decrease in $\beta$-sheet structure. In the presence of MT at $\mathrm{pH} 4.0$ and 9.0, a decrease in fluorescence intensity was observed. Tryptophan fluorescence quenching experiments were also performed using acrylamide and KI as quenchers. Under acidic conditions, a four-fold increase in Stern-Volmer constant $\left(\mathrm{K}_{\mathrm{SV}}\right)$ was observed for BSA + MT. At neutral and basic conditions, a decrease in $\mathrm{K}_{\mathrm{SV}}$ values were observed which indicates conformational changes in BSA upon binding MT. These changes are close to the region where the tryptophan residues are located in the protein.
\end{abstract}

Key words — metallothionein, bovine serum albumin, circular dichroism, fluorescence spectroscopy

\section{INTRODUCTION}

Albumin, the most abundant protein in the plasma, is characterized by a low content of tryptophan and methionine, a high content of cysteine and preponderance of charged acidic and basic amino acids. ${ }^{1-5)}$ Bovine serum albumin (BSA) is an example of a mammalian albumin made up of 637 amino acid residues, two of which are tryptophans located at positions 134 and $212 .^{6}$ ) The primary structure of albumin is unusual among extracellular proteins in possessing a single sulfhydryl (Cys-34) group. The structure of albumin at physiological $\mathrm{pH}$ is predominantly $\alpha$-helical (67\%) with the remaining polypeptide occurring in turns and extended or flexible regions between subdomains with no $\beta$-sheets. ${ }^{7)}$ The BSA molecule is made up of three homologous domains (I, II, III) which are divided into nine loops (L1-L9) by 17 disulfide bonds. Each of the domains can be divided into 10 helical segments, $1-6$ for subdomain A and 7-10 for subdomain B. Domains I

*To whom correspondence should be addressed: Institute of Chemistry, University of the Philippines Diliman, Diliman, Quezon City, 1100 Philippines. Tel. \& Fax: +63-2-920-5427; Email: jamesv_upd@yahoo.com and II and domains II and III are connected through helical extensions of 10(I)-1(II) and 10(II)-1(III) creating the two longest helices in albumin. BSA is known to undergo transitions which are dependent on $\mathrm{pH}$. BSA exists predominantly in the $\mathrm{F}, \mathrm{N}$ and $\mathrm{B}$ forms under acidic, neutral and basic conditions, respectively.7)

Perhaps, the most outstanding property of albumin is its ability to bind reversibly an incredible variety of ligands. ${ }^{8-24)}$ Albumin has a high affinity for fatty acids, hematin, bilirubin and a broad affinity for small negatively charged aromatic compounds. It forms covalent adducts with pyridoxal phosphate, cysteine, glutathione, and various metals such as $\mathrm{Cu}(\mathrm{II}), \mathrm{Ni}(\mathrm{II}), \mathrm{Hg}(\mathrm{II}), \mathrm{Ag}(\mathrm{I})$, and $\mathrm{Au}(\mathrm{I})$. Albumin is also the key carrier or reservoir of nitric oxide, which has been implicated in a number of important physiological processes, including neurotransmission. ${ }^{25)}$

The function of albumin as a carrier protein, responsible for the transport of many ligands including heavy metals, led the authors to study its interaction with metallothionein (MT) which is also a metal-binding protein. Metallothioneins are proteins containing 60-68 amino acid residues, among them 20 cysteines, and binding a total of seven equiva- 
lents of bivalent metal ions. ${ }^{26)}$ Studies have shown that zinc $^{27)}$ and/or copper ${ }^{28)}$ were often found to be the metal ions of MT, indicating their major role in the metabolism and disposition of these biologically essential metals. MT also binds with cadmium, lead and mercury. MT differs from most other metalloproteins by the large number of metal ions it can bind with, unusual number of cysteines, and their high kinetic lability, properties now believed to enable MT to function in metal transfer and different regulatory processes. ${ }^{29-31)}$ This study investigated the interaction between BSA and MT using circular dichroism and fluorescence spectroscopy in order to better understand heavy metal transport and detoxification where these proteins are involved.

\section{MATERIALS AND METHODS}

\begin{abstract}
Sample Preparation — BSA stock solution was prepared by dissolving solid BSA (Sigma catalog number A7638) in deionized water to make a final concentration of $10 \mu \mathrm{M}$. MT stock solution was prepared by dissolving MT (Sigma catalog number M7641) in deionized water to make a final concentration of $5 \mu \mathrm{M}$. Sample solutions for all analyses were prepared by mixing aliquots of BSA and MT such that a final concentration of $5 \mu \mathrm{M}$ for albumin and $1 \mu \mathrm{M}$ for MT were reached. Ionic strength was adjusted using $\mathrm{NaCl}$. In all solutions the buffer concentration was $50 \mathrm{mM}$ while $\mathrm{NaCl}$ concentration was $100 \mathrm{mM}$. Acetate-acetic acid buffer was used for solutions buffered at $\mathrm{pH} 4.0$, phosphate buffer for $\mathrm{pH} 7.0$ and Tris- $\mathrm{ClO}_{4}^{-}$for $\mathrm{pH}$ 9.0.
\end{abstract}

\section{Far UV Circular Dichroism Measurements}

Samples for circular dichroism (CD) measurement were prepared as described in Sample Preparation. Measurements were made using a Jasco J-600 spectropolarimeter using a 1-mm cell. Scans were made from 190 to $280 \mathrm{~nm}$ with a slit width of $1 \mathrm{~mm}$, speed of $20 \mathrm{~nm} / \mathrm{min}$, step resolution of $0.5 \mathrm{~nm}$ and a response time of $16 \mathrm{sec}$. Plots of $\theta$ (molar ellipticity) against wavelength in $\mathrm{nm}$ were constructed from the data. The fractional content of the secondary structure elements of the protein was calculated from the far-UV CD spectra using CDSSTR software with a set of 43 reference proteins.

Fluorescence Spectroscopy — Fluorescence measurements were made with a Shimadzu fluorescence spectrometer. All spectra were recorded in a $1-\mathrm{cm}$ cell with the excitation and the emission slit width set to $3 \mathrm{~nm}$. Excitation wavelength of $295 \mathrm{~nm}$ was routinely used to ensure that the light was absorbed almost entirely by the tryptophan residues of BSA. Fluorescence emission was recorded from $280-500 \mathrm{~nm}$. Plots of fluorescence intensity against wavelength were made from the data.

Tryptophan Fluorescence Quenching Quenching of the tryptophan residues of BSA were done using acrylamide and KI as quenchers. For the solutions of BSA at $\mathrm{pH} 4.0,7.0$ and 9.0, $100 \mu \mathrm{l}$ increments of the quencher were added and the emission signals at $344 \mathrm{~nm}$ (excitation wavelength at $295 \mathrm{~nm}$ ) were recorded after each addition of the quencher. Titration of the solution and measurement of its fluorescence were carried out until the concentration of the quencher reached $0.25 \mathrm{M}$. The whole process was repeated for the solution containing BSA + MT at pH 4.0, 7.0, and 9.0. Stern-Volmer plots were constructed using the corrected fluorescence data taking into account the effect of dilution.

\section{RESULTS AND DISCUSSION}

\section{Far-UV Circular Dichroism}

In order to study the interaction of BSA and MT, circular dichroism was used. The technique is very appropriate because BSA has a high percentage of $\alpha$-helical structure which shows a characteristic CD signal in the far-UV region. On the other hand, MT does not show such a $\mathrm{CD}$ signal being a random coil protein. Changes in the ellipticity at $222 \mathrm{~nm}$ are useful probes for visualizing varying $\alpha$-helical content. By following the changes in ellipticity of BSA with and without MT, the interaction of the two proteins can be assessed. Figure 1 shows the CD spectra of BSA with and without MT at $\mathrm{pH}$ 4.0, 7.0 and 9.0. $\mathrm{BSA}$ at the indicated $\mathrm{pH}$ values exhibited negative absorption bands with maxima at around $222 \mathrm{~nm}$ and $208 \mathrm{~nm}$ consistent with its highly $\alpha$-helical secondary structure. Increase in ellipticity of BSA between $210-240 \mathrm{~nm}$ was observed indicating a slight reduction of $\alpha$-helical content and an increase in $\beta$-structural elements as $\mathrm{pH}$ decreased from $\mathrm{pH} 7.0$ to 4.0. These results were further supported by secondary structure resolved analyses using CDSSTR as presented in Table 1. At pH 7.0, BSA had a fraction of $0.552 \alpha$-helix and $0.191 \beta$-sheet. At $\mathrm{pH} 4.0$, the $\alpha$ helix fraction was reduced to 0.457 and the $\beta$-sheet fraction was increased to 0.285 . Also an increase in random coil structure of BSA was observed as $\mathrm{pH}$ decreased from 7.0 to 4.0. These changes in secondary structure are in accordance with the N-F transi- 

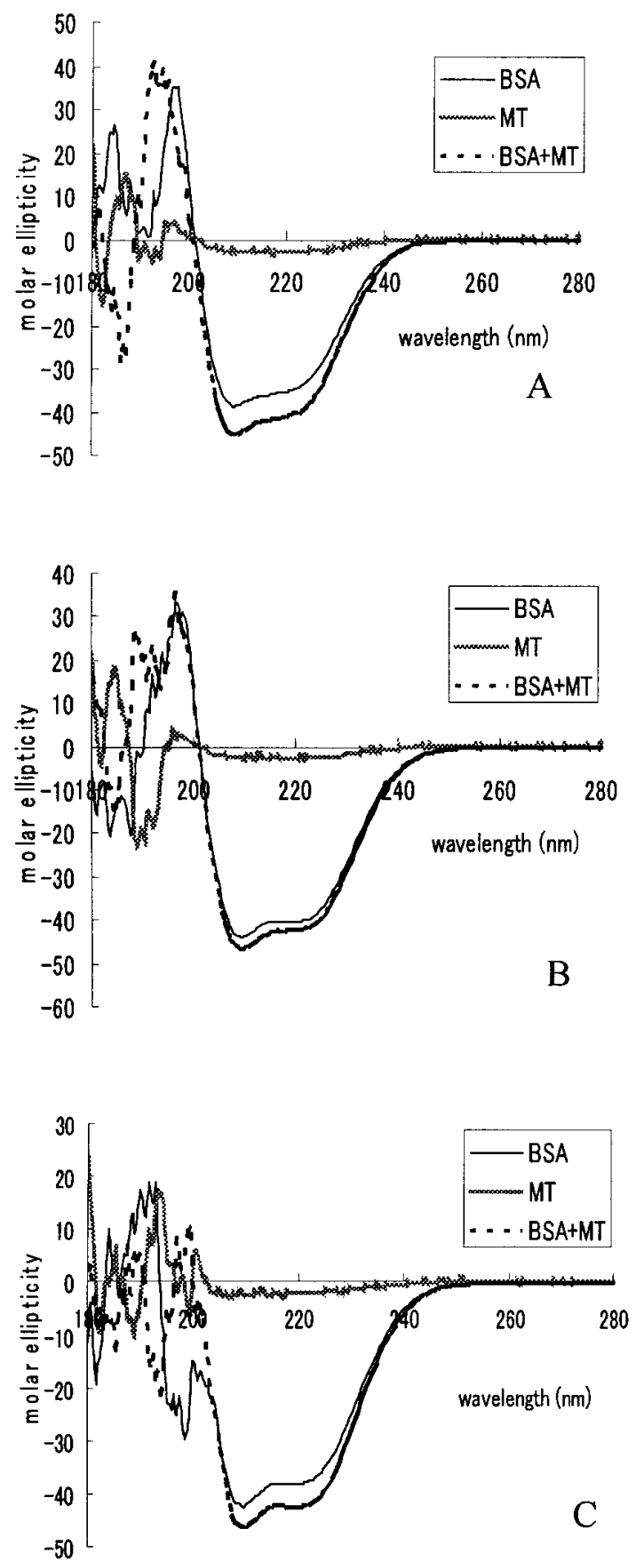

Fig. 1. CD Spectra of MT and BSA with and without MT at (A) pH 4.0 (B) $\mathrm{pH} 7.0$ and (C) $\mathrm{pH} 9.0$

Concentration of BSA was kept at $5 \mu \mathrm{M}$. Measurements were done at $25^{\circ} \mathrm{C}$. tion of BSA at this $\mathrm{pH}$ range. ${ }^{32,33)}$ This N-F transition represents helix $\rightarrow \beta$ and a helix $\rightarrow$ coil transition. The results were also consistent with the fact that the $\mathrm{N}$ state of BSA is approximately $55 \% \alpha-$ helix and $\mathrm{F}$ state is only $45 \% \alpha$-helix. In the alkaline $\mathrm{pH}$ range between 7.0 to 9.0, BSA displayed increased ellipticity which also suggested a reduction in helical content. As shown in Table 1, the fraction of $\alpha$-helix of BSA decreased from 0.552 at $\mathrm{pH} 7.0$ to 0.464 at $\mathrm{pH} 9.0$. The fraction of $\beta$-sheet on the other hand increased from 0.191 to 0.286 at the same $\mathrm{pH}$ range while the coil structure increased slightly from 0.193 at $\mathrm{pH} 7.0$ to 0.199 at $\mathrm{pH}$ 9.0. These findings are in good agreement with the concept of the well known N-B transition of BSA at this $\mathrm{pH}$ range. ${ }^{33,34)}$

In the presence of MT, BSA behaved differently. As shown in Fig. 1A, at pH 4.0, a slight decrease in ellipticity was observed indicating a small increase in the $\alpha$-helical structure of BSA in the presence of MT. CDSSTR results showed that the helicity of BSA increased by 0.005 while the fraction of $\beta$-structure decreased by 0.012 in the presence of MT. Also an increase of 0.007 in coil structure was observed.

At $\mathrm{pH}$ 7.0, similar results were observed as shown in Fig. 1B. In the presence of MT, the $\alpha$-helical content of BSA increased to 0.606 as compared to 0.552 without MT. The fraction of $\beta$-sheet of BSA decreased to 0.163 from 0.191 in the presence of MT. However, a decrease in coil structure of BSA with MT by 0.009 was observed. The results of $C D$ measurements at $\mathrm{pH} 9.0$ (Fig. 1C) were similar to those observed at $\mathrm{pH}$ 4.0. In the presence of MT, BSA showed an increase in $\alpha$-helical structure, a decrease in $\beta$-sheet, and an increase in random coil structure.

The changes in secondary structures of BSA in the presence of MT clearly suggest the interaction of the two proteins. These results show that binding of MT with BSA leads to a change in the conformation of BSA. At pH 7.0, the interaction of MT with BSA causes stabilization of the conformation of BSA

Table 1. Fractional Content of the Secondary Structure of Elements of BSA with and without MT at Varying pH Calculated Using CDSSTR

\begin{tabular}{cccccccccc}
\hline \hline $\mathrm{pH}$ & \multicolumn{4}{c}{$\mathrm{BSA}$} & & \multicolumn{4}{c}{ BSA + MT } \\
\cline { 2 - 3 } \cline { 8 - 10 } & $\mathrm{f}_{\alpha}$ & $\mathrm{f}_{\beta}$ & $\mathrm{f}_{\text {turn }}$ & $\mathrm{f}_{\text {random }}$ & $\mathrm{f}_{\alpha}$ & $\mathrm{f}_{\beta}$ & $\mathrm{f}_{\text {turn }}$ & $\mathrm{f}_{\text {random }}$ \\
\hline 4.0 & 0.457 & 0.285 & 0.068 & 0.205 & & 0.462 & 0.273 & 0.072 & 0.212 \\
7.0 & 0.552 & 0.191 & 0.061 & 0.193 & & 0.606 & 0.163 & 0.052 & 0.184 \\
9.0 & 0.464 & 0.286 & 0.060 & 0.199 & & 0.473 & 0.261 & 0.062 & 0.207 \\
\hline
\end{tabular}


as indicated by a decrease in random coil structure. BSA exists predominantly in the $\mathrm{F}$ form at $\mathrm{pH} 4.0$, in the $\mathrm{N}$ form at $\mathrm{pH} 7.0$ and in the $\mathrm{B}$ form at $\mathrm{pH}$ 9.0. ${ }^{32,33)}$ The different changes in secondary structures upon binding of MT to BSA at varying $\mathrm{pH}$ values as shown by far-UV CD measurements suggest that MT can bind to the F,N, and B forms of $\mathrm{BSA}$ and that this binding does not require the fully native conformation of BSA.

\section{Fluorescence Measurement}

To further investigate the interaction between BSA and MT, fluorescence experiments were performed. Fluorescence spectroscopy is a suitable technique to study the interaction between these two proteins because BSA has two tryptophan residues at positions 134 and 212 while MT does not contain any tryptophan nor other aromatic amino acids. The position of the energy maximum $(\lambda \max )$ from the arising emission spectrum depends on the properties of the environment of the tryptophanyl residue. ${ }^{35)}$ The fluorescence intensity, on the other hand, depends upon the degree of exposure of the tryptophan side chain to a polar solvent and its proximity to specific quenching groups, such as protonated carbonyl, protonated imidazole, deprotonated $\varepsilon$-amino groups and tyrosinate anions. ${ }^{36,37)}$ To examine the conformational variations around the tryptophan residues of BSA as a result of binding with MT, solutions of BSA with and without MT were excited at $295 \mathrm{~nm}$ which provide no excitation of tyrosine residues and the fluorescence emission intensity were recorded. Changes in emission maxima and fluorescence intensity were observed to asses the interaction of BSA and MT. Figure 2 shows the fluorescence emission spectra of BSA with and without MT.

To correctly assess the interaction of BSA and MT, the fluorescence emission spectrum of BSA alone and the spectrum of MT alone were added and the resulting spectrum was compared to the spectrum of a solution containing both BSA and MT. This was done to all the spectra at the different $\mathrm{pH}$ levels. The fluorescence intensities of BSA alone at $\mathrm{pH} 4.0$ and 9.0 were both lower than the fluorescence intensity at $\mathrm{pH}$ 7.0. It was discussed earlier that the far-UV CD signals showed a decrease in $\alpha$-helical content as the $\mathrm{pH}$ decreased from $\mathrm{pH} 7.0$ to 4.0 and increased from $\mathrm{pH} 7.0$ to 9.0. These results are in agreement with the reports of Cowgill ${ }^{38)}$ that loss of helical conformation of BSA is correlated with a decrease in fluorescence intensity.
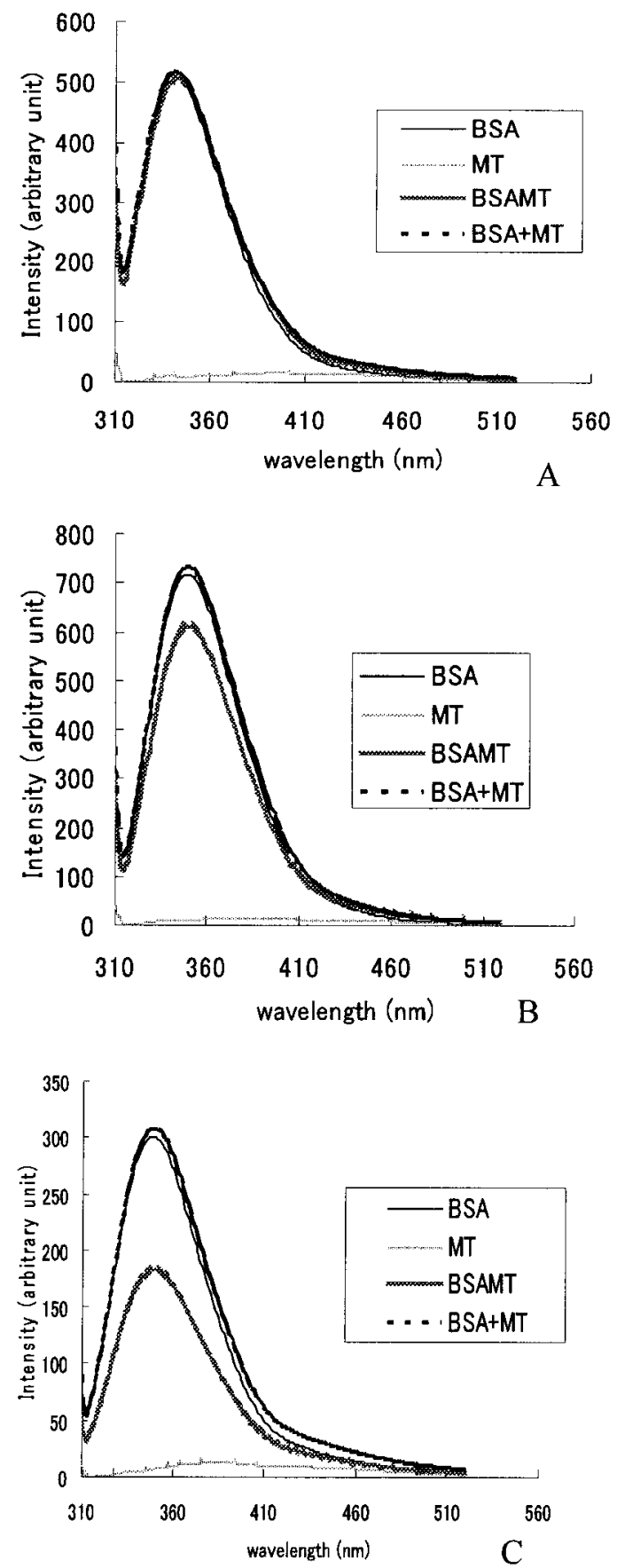

Fig. 2. Fluorescence Spectra of MT and BSA with and without $\mathrm{MT}$ at (A) pH 4.0; (B) pH 7.0 and (C) pH 9.0

BSA + MT represents the sum of the spectra of BSA alone and MT alone while BSAMT represents the spectrum of the solution containing both BSA and MT. Excitation wavelength was $295 \mathrm{~nm}$. Measurements were done at $25^{\circ} \mathrm{C}$

At $\mathrm{pH}$ 4.0, the fluorescence spectrum of BSA in the presence of MT was slightly lower than the fluorescence of BSA alone as shown in Fig. 2A. A slight blue shift $(1 \mathrm{~nm})$ in the emission $\lambda$ maximum of BSA was also observed in the presence of MT. These results suggest that binding of MT with BSA at $\mathrm{pH} 4.0$ 
is associated with changes in the dielectric environment of at least one of the tryptophan residues of BSA. A decrease in intensity of BSA was observed in the presence of MT at $\mathrm{pH} 7.0$ (Fig. 2B). At pH 9.0, a slight blue shift $(1 \mathrm{~nm})$ in $\lambda_{\max }$ of BSA with MT was observed and a very large decrease in fluorescence intensity was also seen in the presence of MT (Fig. 2C).

The decrease in fluorescence intensity of BSA in the presence of MT at $\mathrm{pH} 4.0,7.0$ and 9.0 is due to changes in the secondary structure resulting in the change in environment of the tryptophan residues of BSA. It is also possible that the decrease in fluorescence was due to groups that were brought in close proximity to the indole chromophore as a result of the binding. The effect on tryptophan fluorescence strongly indicates binding between BSA and MT.

\section{Tryptophan Fluorescence Quenching}

The fluorescence and far-UV CD measurements showed conformational changes in BSA in the presence of MT. To further investigate these findings as well as the possible role of tryptophan residues of BSA on its interaction with MT, tryptophan fluorescence quenching experiments were conducted. As stated earlier, BSA has two tryptophan residues: Trp134 and Trp-212 which are located in subdomains IB and IIA, respectively. Trp-134 is thought to be more solvent-exposed than Trp-212. ${ }^{6}$ Trp-212 is analogous to Trp-214, the sole tryptophan of human serum albumin, which is also not in a solvent-exposed environment. ${ }^{6}$ Fluorescence quenching of BSA with and without MT will reveal the conformational changes around the tryptophan residues of BSA upon binding MT. Also these experiments will illustrate whether MT's binding with BSA will lead to a conformational change in BSA causing the burial of the more exposed Trp-134 and/or exposure of the buried Trp-212. Two quenchers were used namely acrylamide and KI. Acrylamide is an efficient quencher of Trp fluorescence and can distinguish between buried and exposed side chains. In contrast, $\mathrm{KI}$ is a highly hydrated and charged chemical species exhibiting a quenching ability limited to surface exposed tryptophans. Quenching by KI is also dependent upon the neighboring charged groups..$^{39,40)}$ Stern-Volmer plots were done using the equation:

$$
\mathrm{F}_{0} / \mathrm{F}=1+\mathrm{K}_{\mathrm{SV}}[\mathrm{Q}]
$$

where $\mathrm{F}$ and $\mathrm{F}_{0}$ are the fluorescence intensities with
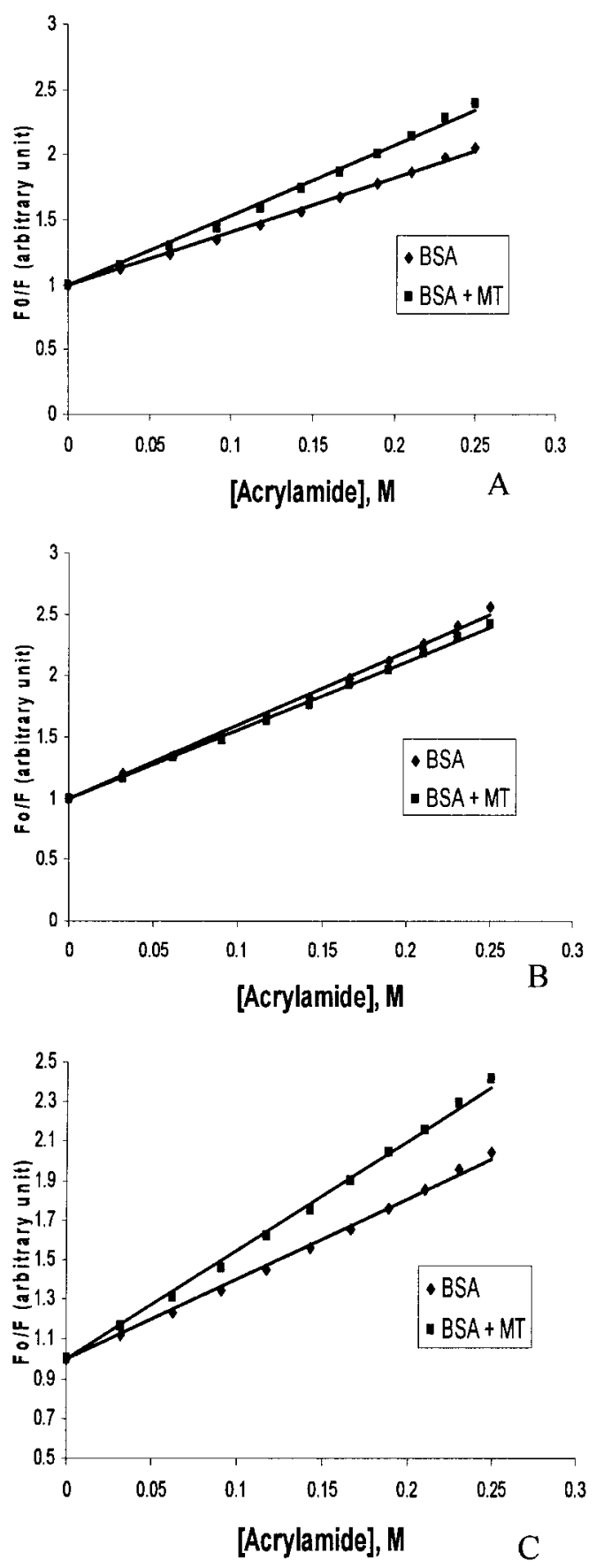

Fig. 3. Fluorescence Quenching of BSA with and without MT by Acrylamide at (A) $\mathrm{pH} 4.0$ and $(\mathrm{B}) \mathrm{pH} 7.0$ and $(\mathrm{C})$ pH 9.0

Increments $(100 \mu \mathrm{l})$ of acrylamide were added to the protein solution until the concentration of acrylamide reached $0.25 \mathrm{M}$. Excitation wavelength was $295 \mathrm{~nm}$.

and without the quencher, respectively, $\mathrm{K}_{\mathrm{SV}}$ is the quenching constant, and $\mathrm{Q}$ is the molar concentration of the quencher. Figure 3 shows the SternVolmer plots using acrylamide as quencher while Fig. 4 shows plots with $\mathrm{KI}$ as quencher. 

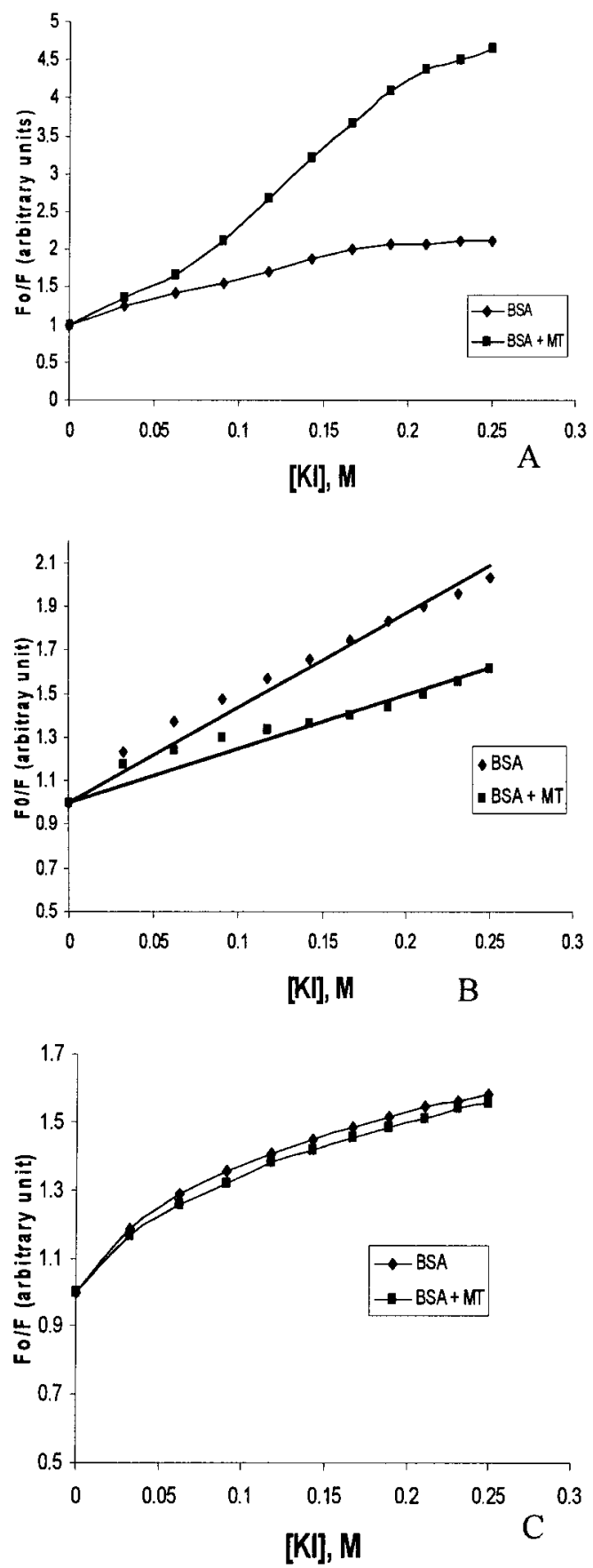

Fig. 4. Fluorescence Quenching of BSA with and without MT by $\mathrm{KI}$ at (A) $\mathrm{pH} 4.0$ (B) $\mathrm{pH} 7.0$ and (B) $\mathrm{pH} 9.0$

Increments $(100 \mu \mathrm{l})$ of $\mathrm{KI}$ were added to the protein solution until the concentration of KI reached $0.25 \mathrm{M}$. Excitation wavelength was $295 \mathrm{~nm}$.
At $\mathrm{pH}$ 4.0, using acrylamide as quencher, a linear increase in $\mathrm{F}_{0} / \mathrm{F}$ of BSA was observed in the presence of MT (Fig. 3A). When KI was used as quencher, the $\mathrm{F}_{0} / \mathrm{F}$ of BSA with $\mathrm{MT}$ also increased as shown in Fig. 4A. The increase in relative fluorescence using KI was nonlinear and was more pronounced as compared to when acrylamide was used. The surface accessibility of tryptophan can be assessed by looking at $\mathrm{K}_{\mathrm{SV}}$ or the Stern-Volmer constant. A summary of the $\mathrm{K}_{\mathrm{SV}}$ values for the quenching of BSA with and without MT at varying $\mathrm{pH}$ is shown in Table 2. At $\mathrm{pH} 4.0$, an increase in $\mathrm{K}_{\mathrm{SV}}$ by 1.332 was observed in the presence of MT using acrylamide as quencher. However, a four-fold increase in $\mathrm{K}_{\mathrm{Sv}}$ was observed with MT when KI was used. The increase in $\mathrm{K}_{\mathrm{SV}}$ in the presence of MT suggests the exposure of the tryptophan residues of BSA upon binding with MT. Since accessibility to iodide is generally taken as an effective indication of exposure of a protein side chain, especially tryptophan, to the solvent, ${ }^{41)}$ the large increase in $\mathrm{K}_{\mathrm{SV}}$ in the presence of MT may signify that binding of MT to BSA resulted in the exposure of the buried Trp-212 of BSA.

At $\mathrm{pH}$ 7.0, quenching of BSA with MT by acrylamide and $\mathrm{KI}$ both resulted in a decrease in $\mathrm{F}_{0} / \mathrm{F}$ (Figs. 3B and 4B). The $\mathrm{K}_{\mathrm{sv}}$ value for BSA with MT was slightly lower than $\mathrm{K}_{\mathrm{sv}}$ for BSA alone when acrylamide was used as quencher. On the other hand, a 1.797 decrease in $\mathrm{K}_{\mathrm{Sv}}$ was observed for BSA + MT when KI was used. Based on these results, it is possible that at $\mathrm{pH} 7.0$ binding of BSA with MT caused a structural change in BSA that buried the exposed Trp-134 residue of BSA or MT binds to the site in BSA where Trp-134 is located causing it to be sandwiched and becomes less exposed to the solvent. These possible changes in the structure of BSA upon binding with MT caused the decrease in $\mathrm{K}_{\mathrm{SV}}$ when KI was used since KI quenching ability is limited only to surface exposed tryptophan. The almost equal $\mathrm{K}_{\mathrm{SV}}$ values for BSA and BSA + MT when acrylamide was used is due to the fact that acrylamide can quench both buried and exposed tryptophan.

Table 2. Stern-Volmer Constants $\left(\mathrm{K}_{\mathrm{SV}}\right)$ Obtained from the Tryptophan Quenching of BSA with and without MT at Varying pH

\begin{tabular}{|c|c|c|c|c|c|c|}
\hline & \multicolumn{2}{|c|}{ pH 4.0} & \multicolumn{2}{|c|}{ pH 7.0 } & \multicolumn{2}{|c|}{ pH 9.0 } \\
\hline & $\overline{\mathrm{BSA}}$ & $\mathrm{BSA}+\mathrm{MT}$ & BSA & $\mathrm{BSA}+\mathrm{MT}$ & BSA & $\mathrm{BSA}+\mathrm{MT}$ \\
\hline Acrylamide & 4.260 & 5.392 & 6.173 & 5.727 & 4.159 & 5.685 \\
\hline KI & 4.610 & 16.092 & 3.887 & 2.090 & 2.084 & 2.021 \\
\hline
\end{tabular}


An increase in $\mathrm{K}_{\mathrm{sV}}$ by 1.526 in the presence of MT using acrylamide was seen at $\mathrm{pH}$ 9.0. However, using $\mathrm{KI}$, the $\mathrm{K}_{\mathrm{SV}}$ values for BSA alone and BSA + MT were almost the same. The results at $\mathrm{pH} 9.0$ show a different BSA-MT binding pattern at this $\mathrm{pH}$ level. The very slight decrease in $\mathrm{K}_{\mathrm{SV}}$ in the presence of MT, using KI, indicates that binding of MT with BSA at $\mathrm{pH} 9.0$ does not affect the environment of the exposed Trp-134 of BSA.

In conclusion, circular dichroism and fluorescence measurements were performed to determine the interaction between BSA and MT. These spectroscopic probes gave proofs of the interaction of the two proteins. The changes in the $\alpha$-helical and $\beta$ sheet contents of BSA in the presence of MT were indicative of the binding between the two proteins. The slight blue shift in the emission of BSA at $\mathrm{pH} 4.0$ and 9.0 as well as the decrease in fluorescence intensity at all $\mathrm{pH}$ levels in the presence of MT also proved the binding of BSA and MT. The $\mathrm{K}_{\mathrm{Sv}}$ values obtained from the quenching experiments revealed the conformational changes around the two tryptophan residues of BSA as a result of its binding with MT and also suggested the possibility of the involvement of these residues in the interaction of BSA and MT. The interaction between MT and albumin may prove useful in understanding the transport and detoxification of heavy metals.

Acknowledgements The authors would like to thank the Analytical Services Laboratory of the Institute of Chemistry, College of Science, University of the Philippines Diliman for the use of the CD spectropolarimeter and fluorescence spectrometer.

\section{REFERENCES}

1) Brown, J. R. (1977) Structure and evolution of serum albumin. Proc. FEBS Meet., 50, 1.

2) Patterson, J. E. and Geller, D. M. (1977) Bovine microsomal albumin: Amino terminal sequence of bovine proalbumin. Biochem. Biophys. Res. Commun., 74, 1220-1226.

3) McGillivray, R. T. A., Chung, D. W. and Davie, E. W. (1979) Biosynthesis of bovine plasma proteins in a cell-free system. Amino-terminal sequence of preproalbumin. Eur. J. Biochem., 98, 477-485.

4) Reed, R. G., Putnam, F. W. and Peters, T., Jr. (1980) Sequence of residues $400-403$ of bovine serum albumin. Biochem. J., 191, 867-868.

5) Hirayama, K., Akashi, S., Furuya, M. and Fukuhara,
K. I. (1990) Rapid confirmation and revision of the primary structure of bovine serum albumin by ESIMS and FRIT-FAB LC/MS. Biochem. Biophys. Res. Commun., 173, 639-646.

6) Peters, T. (1985) Serum Albumin. Adv. Protein Chem., 37, 161-245.

7) Carter, D. C. and Ho, J. X. (1994) Structure of Serum Albumin. Adv. Protein Chem., 45, 153-203.

8) Goodman, D. S. (1958) The Interaction of Human Serum Albumin with Long-chain Fatty Acid Anions. J. Am. Chem. Soc., 80, 3802-3808.

9) Daughaday, W. H. (1959) Steroid Protein Interactions. Physiol. Rev., 39, 885-902.

10) Yates, F. E. and Urguhart, J. (1962) Control of Plasma concentrations of Adrenocortical Hormones. Physiol. Rev., 42, 359-443.

11) Jacobsen, J. (1969) Binding of Bilirubin to Human Serum Albumin-Determination of the Dissociation constants. FEBS Lett., 5, 112-114.

12) Klopfenstein, W. E. (1969) Enthalpy change of binding lysolecithin to serum albumin. Biochim. Biophys. Acta, 181, 323-325.

13) Burke, C. W., Lewis, B., Panveliwalla, D. and Tabaqchali, S. (1971) The Binding of Cholic Acid and its taurine conjugate to serum Proteins. Clin. Chim. Acta, 32, 207-214.

14) Unger, W. G. (1972) Binding of Prostaglandin to human serum albumin. J. Pharm. Pharmacol., 24, 470-477.

15) Westphal, U. and Harding, G. B. (1973) Steroid-Protein Interactions. XXVII. Progesterone Binding to Polymers of Human Serum Albumin. Biochim. Biophys. Acta, 310, 518-527.

16) Beaven, G. H., Chen, S. H., D'Albis, A. and Gratzer, W. D. (1974) A Spectroscopic Study of the HaeminHuman-Serum-Albumin in solution studied by Small-Angle Neutron Scattering. Eur. J. Biochem., 41, 539-546.

17) Jacobsen, J. (1977) Studies of the affinity of $\mathrm{Hu}-$ man Serum Albumin for Binding of Bilirubin at different Temperatures andionic strength. Int. J. Pept. Protein Res., 9, 235-239.

18) Richardson, K. S. C., Nowaczynski, W. and Genest, J. (1977) Specific Aldosterone-Binding Proteins in Human Plasma: Partial Characterisation. J. Steroid Biochem., 8, 951-957.

19) Spector, A. A. and Fletcher, J. E. (1978) Transport of Fatty Acid in Circulation. In Disturbances in Lipid and Lipoprotein Metabolism (Dietschy, J. M., Gotto, A. M., Jr. and Ontko J. A., Eds.), American Physiological Society, Rockville, MD, pp. 229-248.

20) Brodersen, R. (1979) Bilirubin. Solubility and Interaction with Albumin and Phospholipid. J. Biol. Chem., 254, 2364-2369. 
21) Adams, P. A. and Berman, M. C. (1980) Kinetics and mechanism of the interaction between human serum albumin and monomeric haemin. Biochem. J., 191, 95-102.

22) Savu, L., Benassasyag, C., Vallette, G., Christeff, N. and Nuney, E. (1981) Mouse a1 - Fetoprotein and Albumin. J. Biol. Chem., 256, 9414-9418.

23) Roda, A., Cappelleri, G., Aldini, R., Roda, E. and Barbara, L. (1982) Quantitative aspects of the interaction of bile acids with human serum albumin. $J$. Lipid Res., 23, 490-495.

24) Emerson, T. E., Jr. (1989) Unique features of albumin: A brief review. CRC Crit. Care Med., 17, 690694.

25) Stamler, J. S., Singel, D. J. and Loscalzo, J. (1992) Biochemistry of Nitric Oxide and its Redox-Activated Forms. Science, 258, 1898-1902.

26) Kagi J. H. R. and Vallee, B. L. (1960) Metallothionein: a cadmium- and zinc- containing protein from equine renal cortex. J. Biol. Chem., 235 , 3460-3465.

27) Aoki, Y., Sunaga, H. and Suzuki, K. T. (1988) A cadmium-binding protein in rat liver identified as ornithine carbamoyl transferase. Biochem. J., 250, 735-742.

28) Palmiter, C. J., Findley, S. D., Erickson, J. C., Froelick, E. J. and Kelly, B. P. (1987) Molecular biology of metallothionein gene expression. Experientia Suppl., 52, 63-80.

29) Suzuki, K. T. (1980) Direct Connection of highspeed liquid chromatography (equipped with gel permeation column) to atomic absorption spectrophotometer for metallothionein analysis. Anal. Biochem., 102, 31-34.

30) Lehman, L. D. and Klasson, C. D. (1986) Separation and quantitation of metallothioneins by highperformance liquid chromatography coupled with atomic absorption spectrophotometry. Anal. Biochem., 153, 305-314.

31) Czupryn, M., Brown., W. E. and Vallee, B. L. (1992)
Zinc rapidly induces a metal response element-binding factor. Proc. Natl. Acad. Sci. U.S.A., 89, 1039510399.

32) Carter, D. C. and Ho, J. X. (1994) Structure of serum albumin. Adv. Protein Chem., 45, 153-203.

33) Peters, T., Jr. (1996) All About Albumin: Biochemistry, Genetics, and Medical Applications, Academic Press, Inc., New York.

34) Era, S., Itoh, K. B., Sogami, M., Kuwata, K., Iwama, T., Yamada, H. and Watari, H. (1990) Structural transition of bovine plasma albumin in the alkaline region - the N-B transition. Int. J. Pept. Protein Res., 35, 1-11.

35) Steinhardt, J., Krijn, J. and Leidy, J. G. (1971) Differences between bovine and human serum albumins: binding isotherms, optical rotatory dispersion, viscosity, hydrogen ion titration, and fluorescence effects. Biochemistry, 10, 4005-4015.

36) Halfman, C. J. and Nishida, T. (1971) Influence of $\mathrm{pH}$ and electrolyte on the fluorescence of bovine serum albumin produced by the binding of dodecyl sulfate. Biochim. Biophys. Acta, 243, 284-293.

37) Halfman, C. J. and Nishida, T. (1971) Nature of the alteration of the fluorescence spectrum of bovine serum albumin produced by the binding of dodecyl sulfate. Biochim. Biophys. Acta, 243, 294-303.

38) Cowgill, R. W. (1968) Fluorescence and protein structure. XV. Tryptophan fluorescence in helical muscle protein. Biochim. Biophys. Acta, 168, 431438.

39) Aust, S. D., Chignell, C. F., Bray, T. M., Kalyanaraman, B. and Mason, R. P. (1993) Free radicals in toxicology. Toxicol. Appl. Pharmacol., 120, 168-178.

40) Kagi, J. H. R. and Schaffer A. (1988) Biochemistry of metallothionein. Biochemistry, 27, 8509-8515.

41) Eftink, M. R. (1991) Fluorescence techniques for studying protein structure. Topics in Fluorescence Spectroscopy, 2, 53-127. 